\title{
Chapter 12 \\ Coparenting Interventions and Shared Physical Custody: Insights and Challenges
}

\author{
Joëlle Darwiche, Cindy Eira Nunes, Nahema El Ghaziri, Camille Imesch, \\ and Séverine Bessero
}

\begin{abstract}
This chapter focuses on the issue of shared physical custody (SPC) in the broader context of coparenting interventions. To identify if and how these interventions address the issue of SPC, we provide a systematic overview of the currently available types of coparenting interventions after marital dissolution. To be selected, the interventions had to be published in peer-reviewed journals, target separated or divorced parents, integrate work on coparenting, and include a custody focus within the intervention curriculum or as a targeted outcome. Finally, they had to be subject to empirical evaluation.

As a second step, using a case study, we investigate how the issue of SPC may be addressed before divorce, during couple therapy. We describe the therapy sessions to highlight the factors that may protect or undermine the development of a cooperative coparenting relationship while separating, and eventually create a positive sharedcustody scenario after divorce. We also analyse the couple's progress regarding individual symptomatology and coparenting satisfaction based on self-reported questionnaires and on the quality of their observed coparenting interactions.

From a therapeutic perspective, this chapter aims to deepen our understanding of the challenges and opportunities of coparenting during and after separation and its intertwinement with the issue of SPC.
\end{abstract}

Keywords Coparenting $\cdot$ Shared physical custody $\cdot$ Intervention $\cdot$ Couple therapy

\footnotetext{
J. Darwiche $(\bowtie) \cdot$ C. E. Nunes · C. Imesch

Family and Development Research Center, Institute of Psychology, University of Lausanne, Lausanne, Switzerland

e-mail: joelle.darwiche@unil.ch; cindy.eiranunes@unil.ch

N. El Ghaziri

Center for Primary Care and Public Health (Unisanté), University of Lausanne, Lausanne,

Switzerland

e-mail: Nahema.El-Ghaziri@unisante.ch

S. Bessero

Couples and Families Therapeutic Consultation, Geneva University Hospitals, Geneva,

Switzerland

e-mail: Severine.Bessero@hcuge.ch
} 


\subsection{Introduction}

In this chapter, we discuss the issue of Shared Physical Custody (SPC) from the perspective of therapeutic coparenting interventions. Coparenting interventions offer therapeutic work focused on the coparenting relationship, meaning the way parents support or undermine each other in relation to their parental duties (McHale and Irace 2011). When separated or divorced couples discuss and plan a SPC scenario, the partners endorse their coparental role. Therefore, we aim to investigate whether and in which way post-separation or divorce coparenting interventions address the issue of custody, and of SPC, in their treatment plan. To answer this question, we provide a systematic overview of the currently available types of coparenting interventions that specifically address the issue of custody and/or that include the issue of custody in their outcomes, while being subject to empirical evaluation. The selected studies define SPC as time that children spent in each home varying from one-third $(70 \% / 30 \%)$ to an equal share $(50 \%)$.

Moreover, we investigate if, ahead of the separation process, the issue of SPC (whether it is an asymmetrical or a split arrangement) is also present during couple therapy. How can separating partners be engaged as coparents, and how does their coparenting dynamic impact the decision process of SPC? To answer this second question, we provide a case study of a distressed couple that has decided to separate during couple therapy. This case study will enable an examination of the possible improvements or setbacks faced by couples in their coparenting relationship during the process of separation. It will also enable reflection on how the matter of custody affects this process and its possible intertwinement with the coparenting relationship.

This work represents a novelty in the field, as the approaches for handling the SPC issue by different coparenting interventions have not yet been explored. Furthermore, it explores via a case study how one can intervene on the coparenting relationship, as well as the role of SPC-related issues, in the couple's trajectory from marriage to divorce. This last aspect could be of interest to professionals involved in either marriage or post-separation counselling.

\subsection{Theoretical and Empirical Framework}

Coparenting is a specific psychological and relational dynamic between the adults in charge of a child or children (Favez 2017). Accordingly, in the context of family developmental psychology, it refers to the emotional experience of being a coparent. It relates to the way parents share leadership, work together to resolve disagreements, and support-or undermine-each other concerning their parental duties (Kamp Dush et al. 2011; McHale and Irace 2011). Several dimensions of coparenting have been identified (Favez 2017): (1) cooperation and support between parents, (2) conflict or competition between parents, (3) effective division of parenting tasks, (4) commitment to parenting, (5) agreement on issues related to child- 
rearing, and (6) triangulation (for example, one parent recruiting the child into a coalition against the other). Effective coparenting is motivated by the well-being of the child or children and may change according to the child's developmental needs. Noticeably, the positive impact of coparenting alliance and the deleterious effect of coparenting conflict have been shown to remain relevant throughout the family lifecycle (e.g. Choi et al. 2019; Martin et al. 2017; Murphy et al. 2016).

Coparenting is one of the most important processes being discussed in contemporary studies on relationships and parenting (McHale and Lindahl 2011; Morril et al. 2010). Child developmental studies have shown that coparenting functioning is a pivotal factor in the intrafamilial dynamic, exerting significant impact on a child's psychological adjustment (e.g. Teubert and Pinquart 2010). Studies concerning intact families (for a review, see Mangelsdorf et al. 2011) as well as those concerning post-divorce families (e.g. Ahrons 2007; Adamsons and Pasley 2006; Pruett et al. 2007) have shown that coparenting quality predicts important developmental processes, such as children's conflictual peer relations, as well as externalising and internalising behavioural problems (Choi et al. 2019; McHale and Lindahl 2011).

Because coparenting is a key aspect of the parents' functioning-for both intact families and separated or divorced families-existing research assumes that it represents a major aspect of the decision-making process concerning shared physical custody evaluations and court decisions (Nielsen 2017). Particularly, when there is a highly conflictual coparenting relationship, SPC is generally not considered the best solution for the children (Wallerstein et al. 2000). However, some authors have warned against placing too much emphasis on coparenting quality in this context, as we do not have the empirical justification to conclude that coparents in conflict should not choose SPC or would not have a successful SPC arrangement (Leclair et al. 2018; Nielsen 2017). While a conflictual coparenting relationship might complicate the experience of SPC or even be deleterious in cases of violence or abuse, the presence of conflict in itself should not be considered as hindering the possibility of a SPC arrangement. Many different factors play a role in realizing a positive SPC experience, such as socio-economic factors as well as relational and psychological factors (Steinbach 2018). SPC promotes the preservation of the parent-child relationship, with research indicating that it is a positive factor in children's adjustment and well-being, even if there are occasional tensions and difficulties in the relationship between their parents (Braver 2014). For that reason, one should not forgo this option without a solid rationale.

Nevertheless-and given the extensive empirical literature showing that coparenting affects a child's outcomes before (e.g. McHale and Lindahl 2011) and after separation or divorce (e.g. Adamsons and Pasley 2006; Lamela and Figueiredo 2016) - interventions supporting the coparenting relationship may be necessary at different stages of transition from marriage to separation or divorce (Pruett and Donsky 2011). During the separation process, the coparenting relationship may be significantly challenged. Parents may experience difficulties due to the spillover effects between marital distress and coparenting disagreements (Stroud et al. 2015). Indeed, as highlighted by the family systems theory, each subsystem (e.g. the romantic relationship) has the potential to affect the other subsystems (e.g. the 
coparenting relationship; Cox and Paley 1997). Regarding the parental couple, some authors suggest that the romantic relationship should be considered a predictor, as it chronologically comes first and represents the basis of trust and support on which the coparental relationship will develop. Substantial studies have found that mothers' and fathers' perceptions of the romantic relationship will not only affect their own coparental behaviour but also the behaviour of their partner (Christopher et al. 2015; Le et al. 2016). More importantly, an experimental study by Kitzmann (2000) revealed that romantic conflict altered the quality of later coparental interactions. Accordingly, one could expect that marital distress associated with separation or divorce may complicate the coparental interactions. However, the opposite may also be true. Feeling undermined in one's parental role or witnessing the other parent disrespecting the rules that were set for the child's education may generate anger and disillusion about the partner, therefore affecting the parents' romantic relationship, as it was shown in intact families (Schoppe-Sullivan et al. 2004). In the context of divorce and separation, spillover effects from romantic distress onto coparenting may first emerge. However, as tensions between parents increase, spillovers could also travel in the opposite direction, from the coparenting subsystem to the romantic one, eventually complicating and/or extending the separation process. This hypothesis highlights the importance of providing interventions that consider these spillover effects from one subsystem to another at the different stages of separation or divorce.

Concerning the question of custody arrangements-and more specifically, the question of SPC - supportive coparenting may have a facilitating role in the agreement process (Sullivan 2008). We may ask the following question: is coparenting a continuous process before, during, and after separation? If this were the case, it would imply that pre-separation cooperative coparenting might be a protective factor in custody arrangements, whereas conflictual coparenting prior to separation might represent a risk factor for any agreement regarding custody. If coparenting is instead a discontinuous process, a separation might affect the previous coparenting relationship either negatively or positively. In the former case, the partners may experience so much marital distress that it prevents coparenting cooperation during the transition to separation and divorce. In the latter case, on the contrary, parents may even improve their coparenting relationship once the decision to separate has been taken. Some data have shown, for example, that the dissolution of marriages with high coparental conflict had less negative effects, or even had positive effects on children, compared to the dissolution of marriages with low interparental conflict (Booth and Amato 2001).

Given the role of coparenting for the family well-being and especially for the child's outcomes, a number of interventions targeting the coparenting relationship have been developed for post-divorce parents. Through our systematic literature review, we aim to identify the programs that included SPC as a topic of discussion and/or as an outcome, to better evaluate the importance that was given to SPC in these treatment programs.

We then take a step back to document, through the case study, how and when the issue of SPC emerged during the therapy of a separating couple. We will explore two hypotheses to get insights on the issue of continuity and/or discontinuity of the 
coparenting relationship pre- and post-divorce: (a) coparenting is a continuous process; cooperative coparenting would be a protective factor whereas conflictual coparenting before separation would be a risk factor for agreement regarding custody; (b) coparenting is a discontinuous process as the decision to separate will noticeably modify the coparenting dynamic, either in a positive or a negative way.

\subsection{Review of Post-separation and/or Divorce Coparenting-Based Programs}

This systematic literature review was carried out to identify the available coparenting-based programs intended for separated and/or divorced parents and to select those that explicitly include the issue of custody as a target of intervention and/or as an outcome.

Previous papers reviewed interventions following separation or divorce (for example, Lee et al. 1994; Pruett and Donsky 2011). However, those reviews either did not focus on coparenting interventions per se or did not specifically target how interventions included custody-related aspects. These reviews showed that numerous resources are available to parents after divorce and that they either draw from the traditional litigation approach (e.g. court-connected services; court-based systemwide interventions) or from the alternative dispute resolution approach (e.g. mediation outside of the court process; parent education programs; Pruett et al. 2011). Depending on the approach, the focus of these programs varies: (1) it can be to reach legal and practical agreements, reduce litigated custody cases, and help parents to implement and comply with their parenting plans (e.g. mediation; parenting coordination); (2) and/or it can be to inform couples about the repercussions of divorce, promote the inclusion of both parents, strengthen the quality of the parent-child relationship and the coparenting relationship, and help the parents to refrain from arguments in the best interest of their children (Pruett and Donsky 2011). It may not be easy for parents, or for mental health professionals, to find their way through the multitude of methods available (see Emery 2012, for a conceptual system of dispute resolution alternatives). In this review, we focus on coparentingbased programs, whatever their setting, to identify the existing interventions targeting the coparenting relationship after separation or divorce. We detail the objectives of these programs and analyse if and how aspects of custody are present as a target of the intervention.

\subsubsection{Method}

Inclusion Criteria Studies were included in the review based on five criteria: (1) in-press or published articles in peer-reviewed journals; (2) programs targeting separated or divorced parents (or those in the process); (3) programs with a 
coparenting focus (e.g. improvement of coparenting support, reduction of coparenting conflict, children caught in the middle), as one of the main aims of the intervention or as a secondary aim; (4) programs including a custody focus within the intervention curriculum or as a targeted outcome; and (5) availability of the program's empirical validation (qualitative and/or quantitative).

This review follows the Cochrane guidelines for conducting a systematic review of interventions (Higgins and Green 2008). The review was carried out by the first three authors, and the final decision regarding the summarized data (see Table 12.1) was reached by consensus.

Literature Search For the purpose of this review, three electronic databases were systematically searched: Pubmed, Web of Science, and APA PsycNET (which combines the databases of PsycINFO, PsycARTICLES, Psyc CRITIQUES, and APA Books). The searches were conducted between December 2018 and January 2019. The following keywords were entered into the three search engines: (co-parent* OR interparent*) AND (therapy OR treatment OR intervention OR program) AND (divorce OR separation).

Selection Procedure The search identified 710 references in the different databases (see Fig. 12.1. Flow chart of the selection process). All resulting references were imported into a citation manager (Zotero 5.0), which removed the duplicates automatically. In addition, some duplicates were removed manually, leaving 573 records. Irrelevant records were removed from screening via title and abstract (screening 1), and then via full-text (screening 2), leaving 48 references and 33 different coparenting-based programs. Then, we identified 16 references and 13 coparenting-based programs specially focusing on custody issues through their program protocol (screening 3); 5 of these 13 programs also included the issue of custody as an outcome. The 13 programs are presented in Table 12.1. Regarding outcomes, only those related to custody are reported.

\subsubsection{Results}

Global Description of the Programs Only a minority of programs are manualised $(\mathrm{N}=5)$, i.e. a handbook was used to guide the intervention, which is recognized as a condition to ensure fidelity for both clinical work and research purposes. A total of 6 programs are mandated programs, at least for a portion of the participants, and the rest are voluntary. The settings vary and include a self-study handbook $(\mathrm{N}=1)$, a mix of individual and joint parent sessions $(\mathrm{N}=2)$, joint parent sessions $(\mathrm{N}=2)$, online interventions $(\mathrm{N}=3)$, and group sessions $(\mathrm{N}=5)$. A total of 2 programs also include sessions with the child or children. The number of sessions ranges from 1 to a maximum of 20 , or $40 \mathrm{~h}$. 


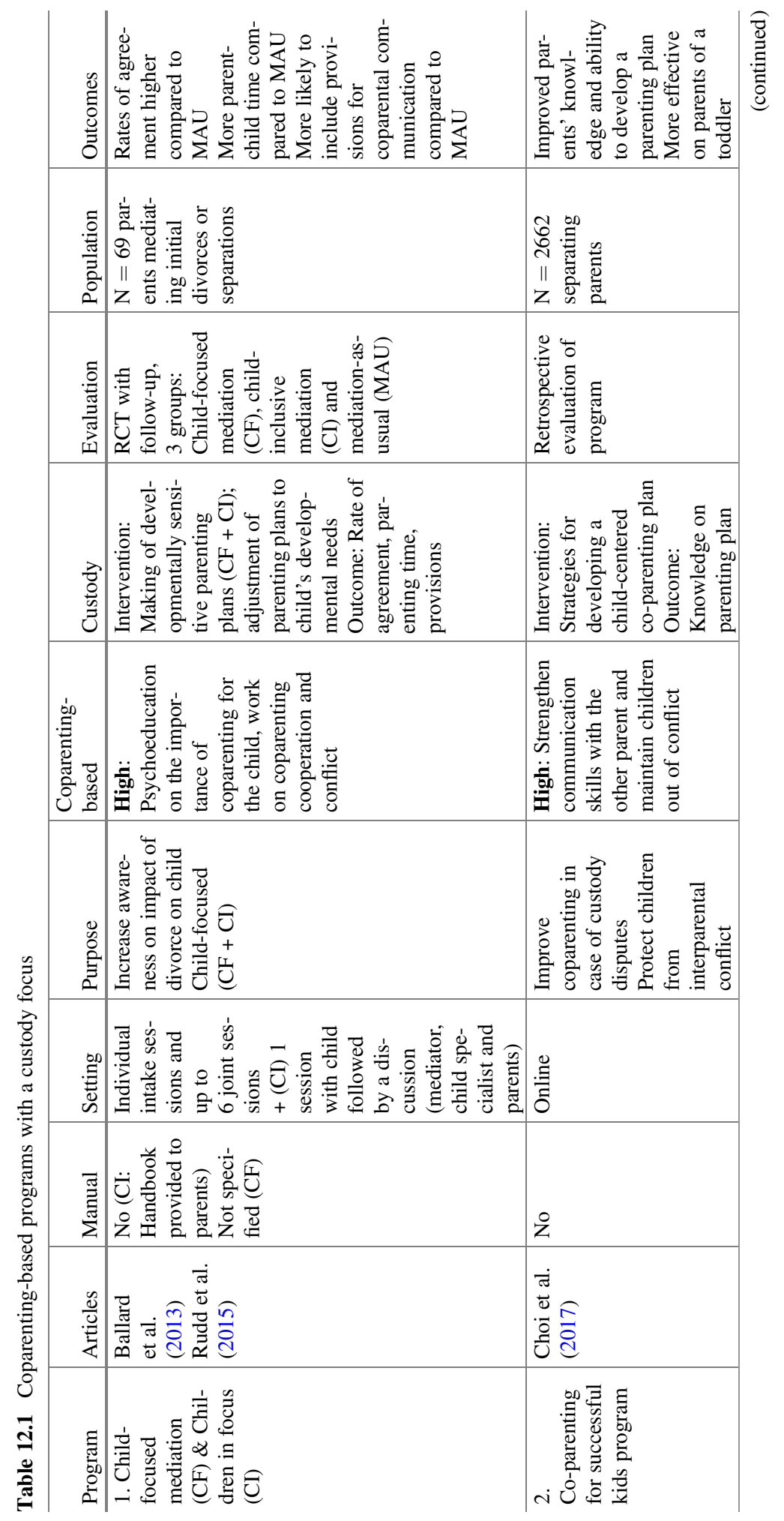




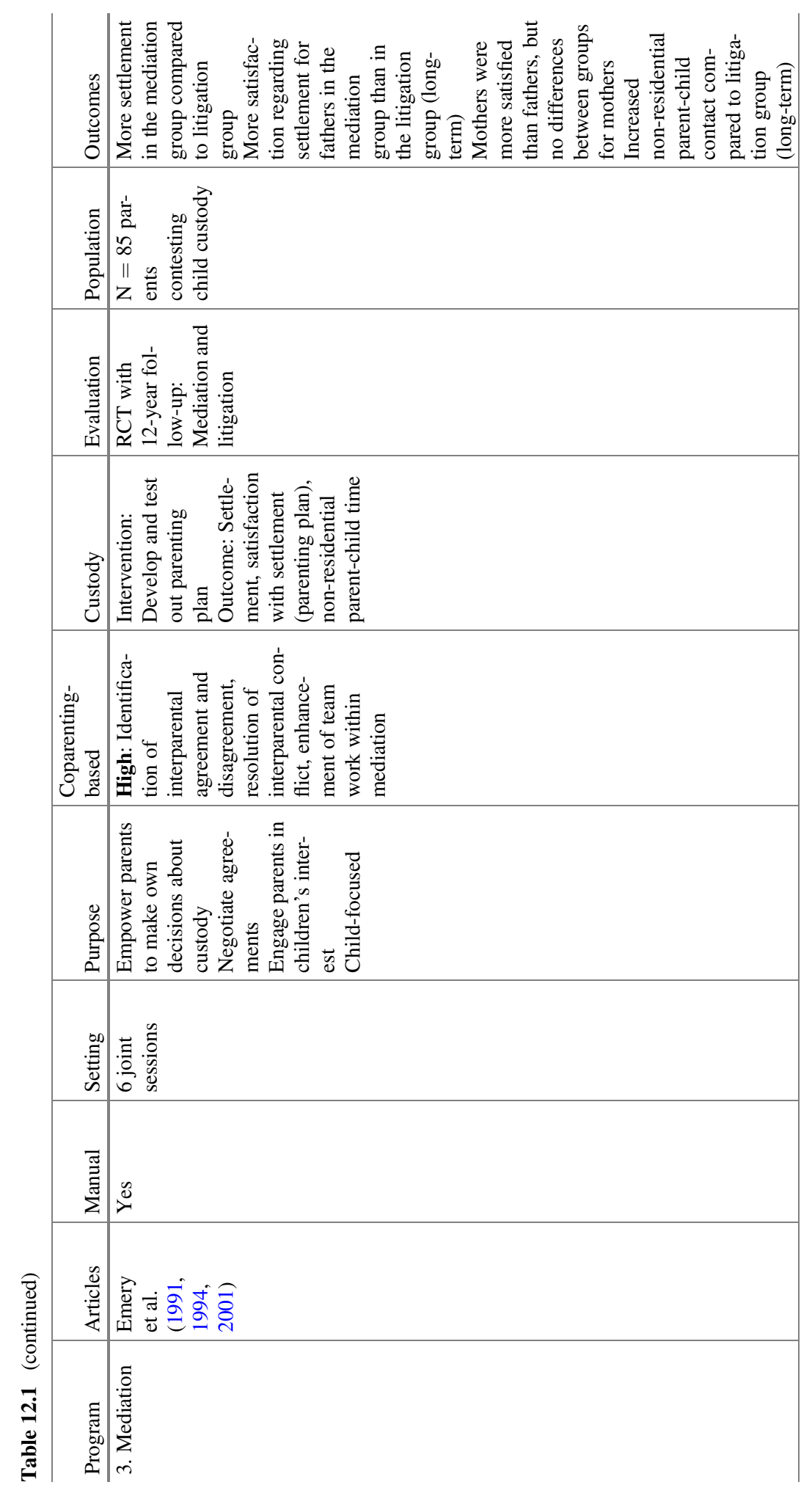




\begin{tabular}{|c|c|c|}
\hline 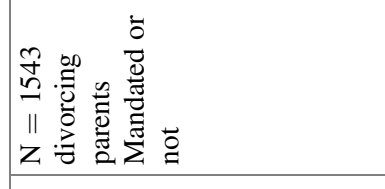 & 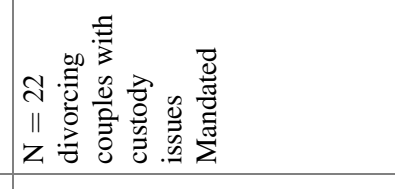 & 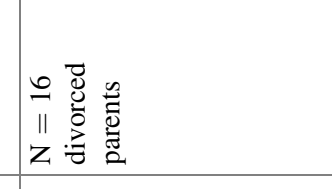 \\
\hline 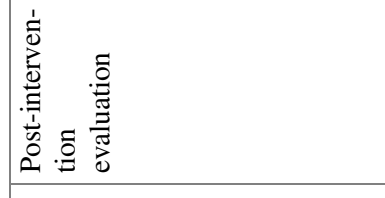 & 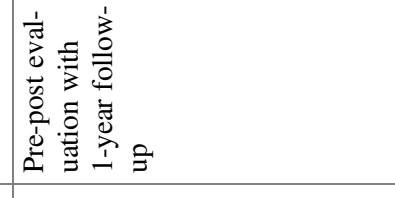 & 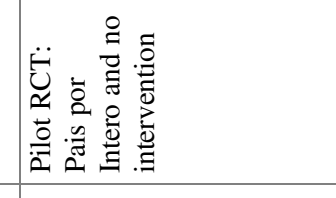 \\
\hline 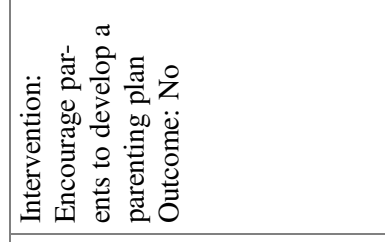 & 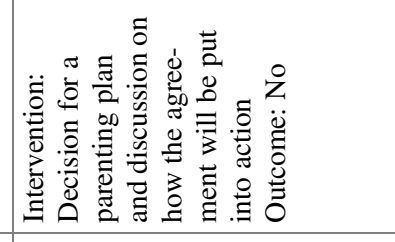 & 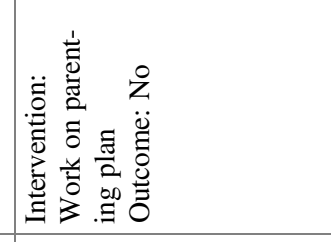 \\
\hline 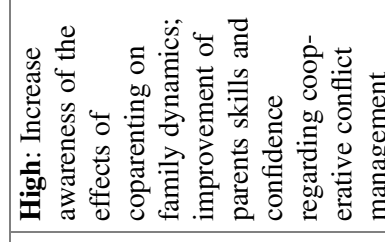 & 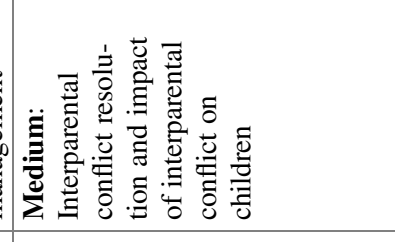 & 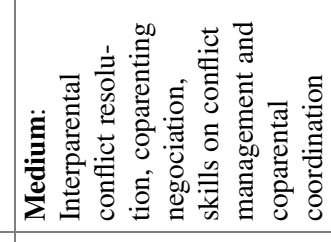 \\
\hline 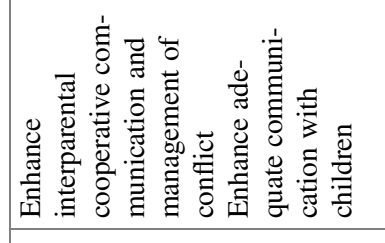 & 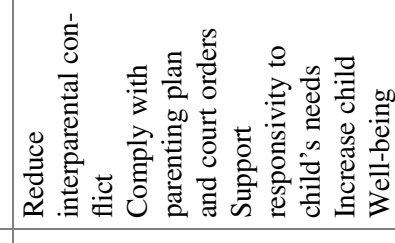 & 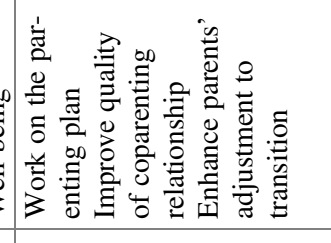 \\
\hline 号 & 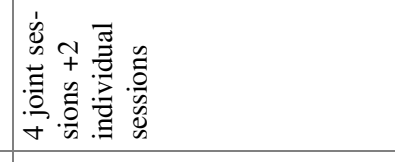 & 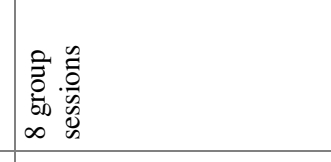 \\
\hline z & z & $\check{\nu}^{\circ}$ \\
\hline 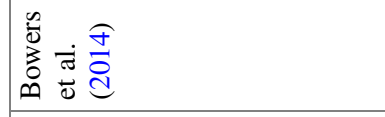 & 言㻤灾 & 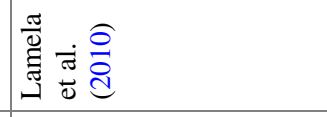 \\
\hline 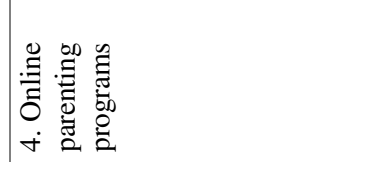 & 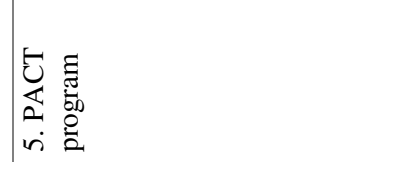 & 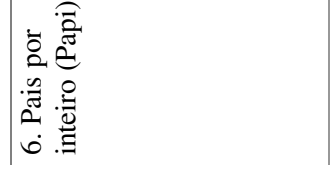 \\
\hline
\end{tabular}




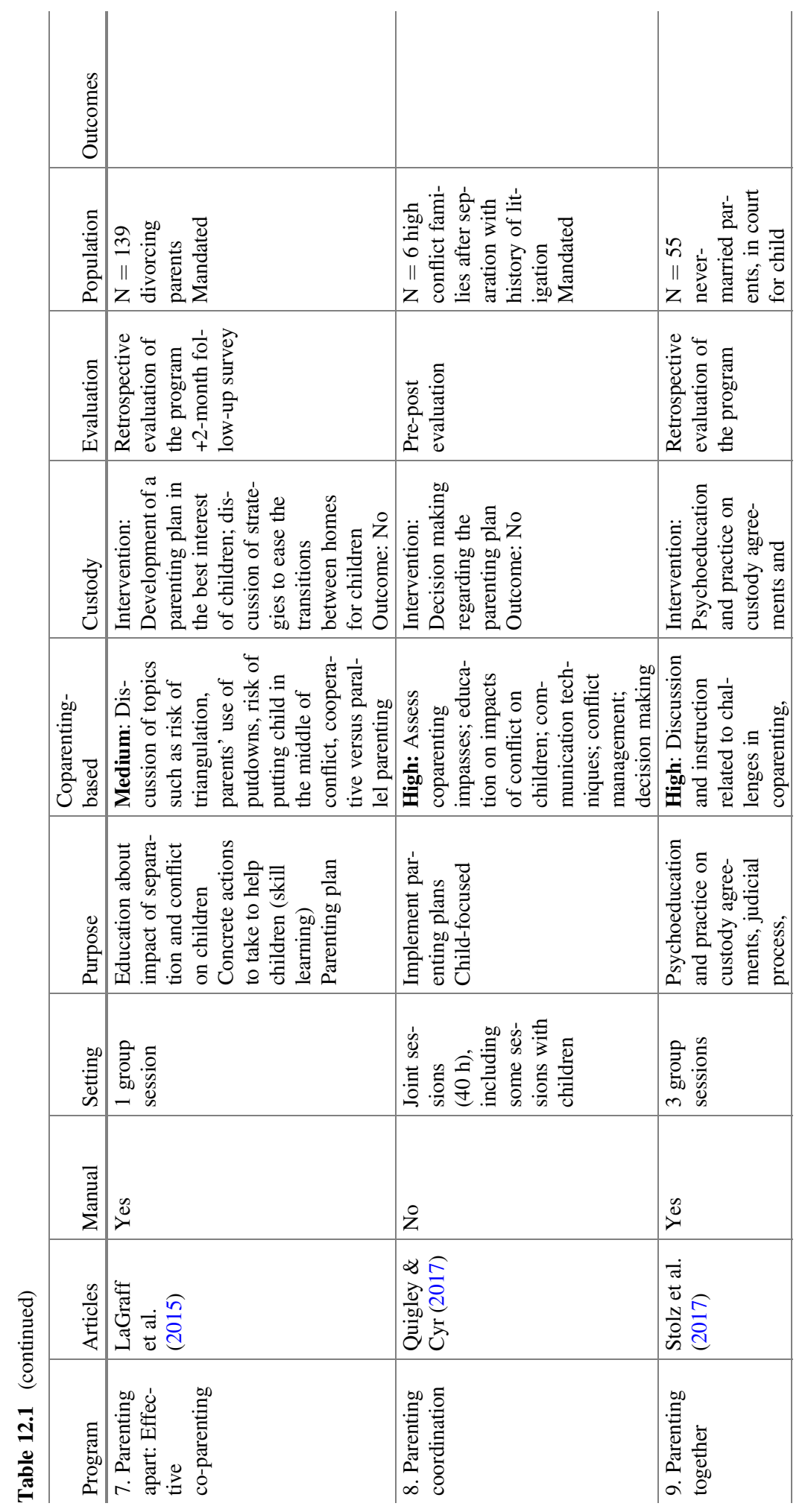




\begin{tabular}{|c|c|}
\hline & 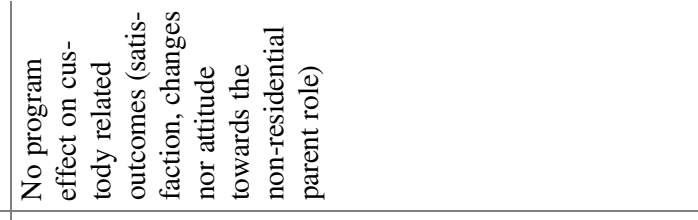 \\
\hline 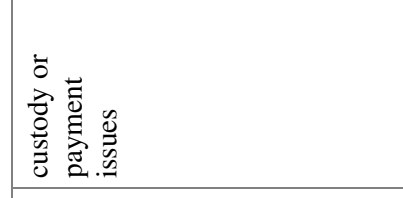 & 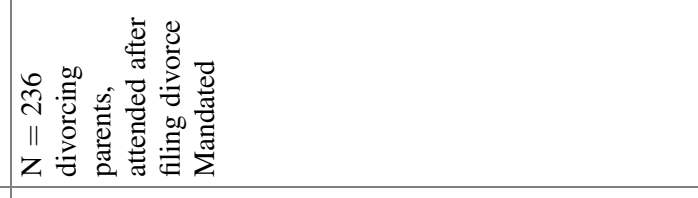 \\
\hline & 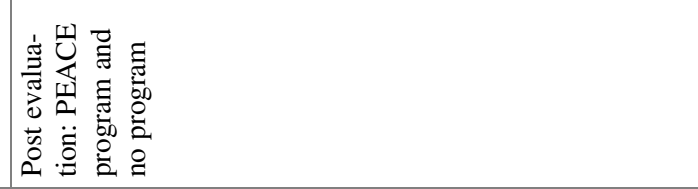 \\
\hline 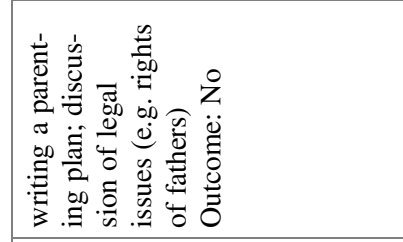 & 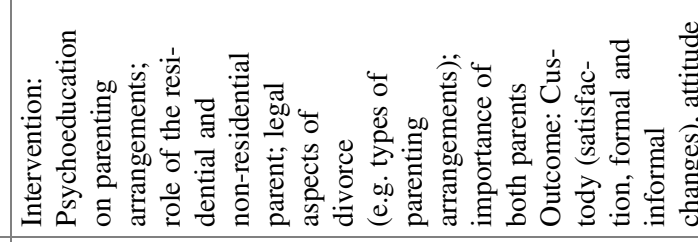 \\
\hline 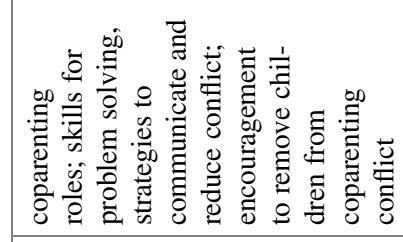 & 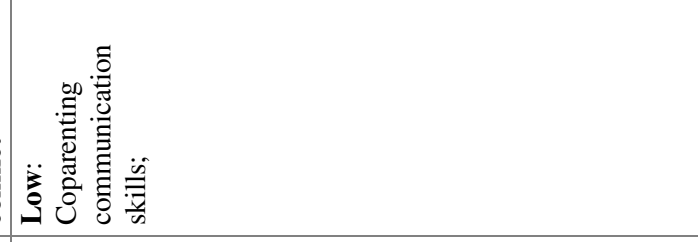 \\
\hline 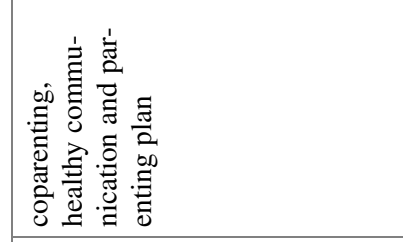 & 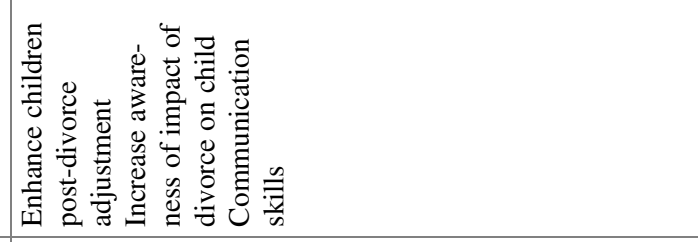 \\
\hline & 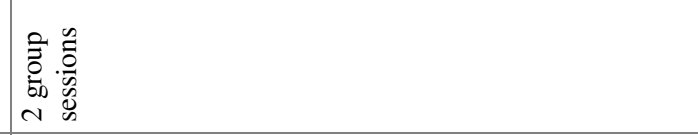 \\
\hline & 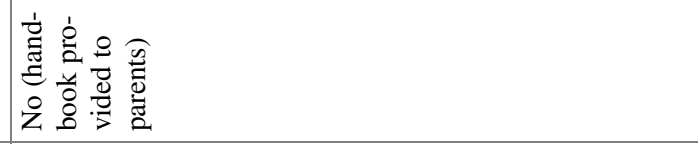 \\
\hline & 㢇 \\
\hline & 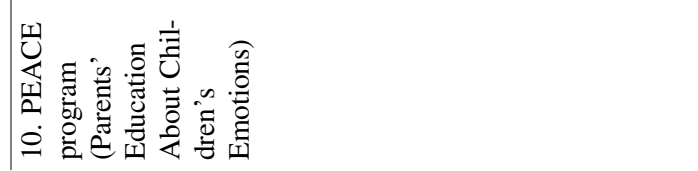 \\
\hline
\end{tabular}




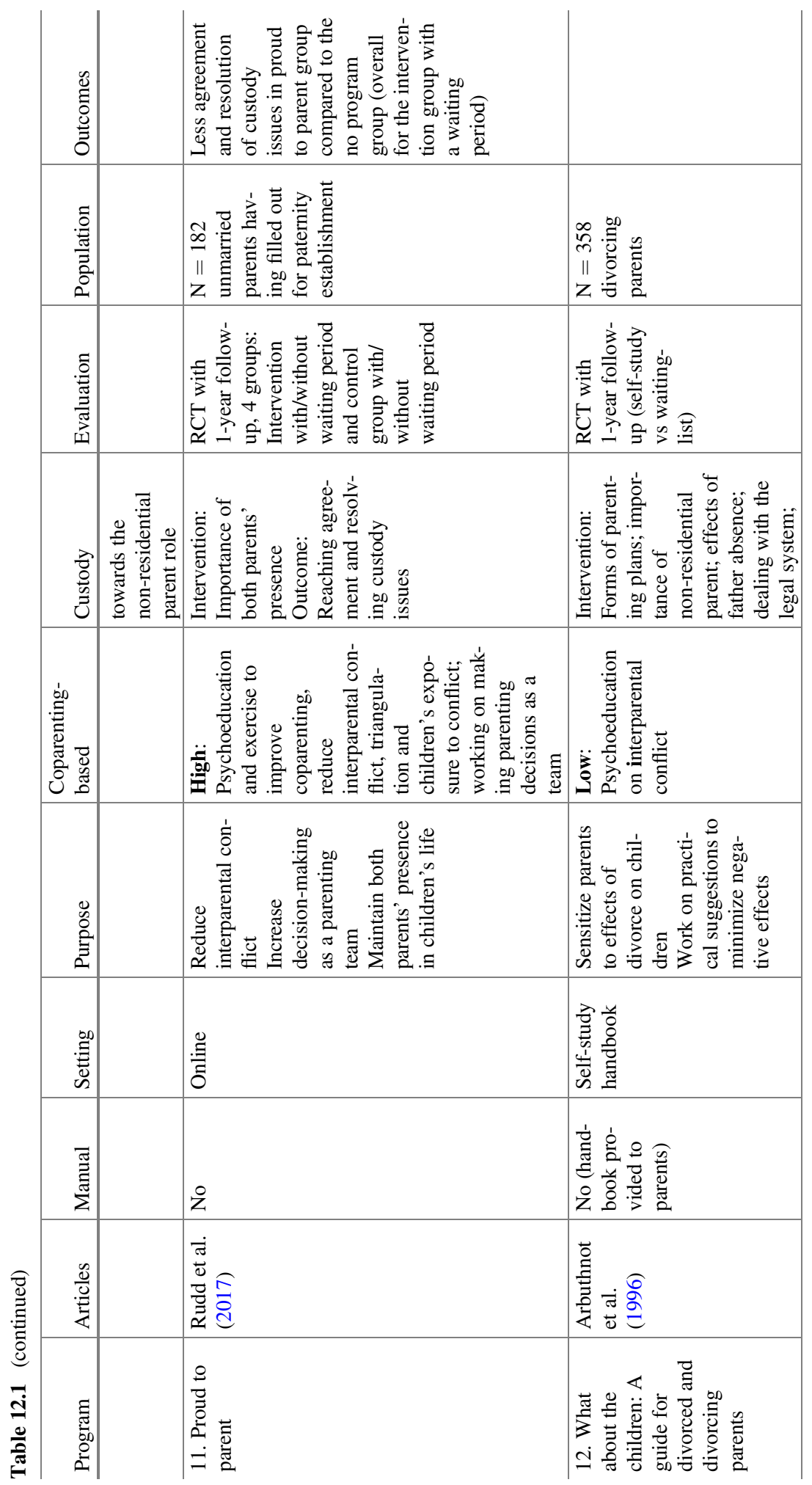




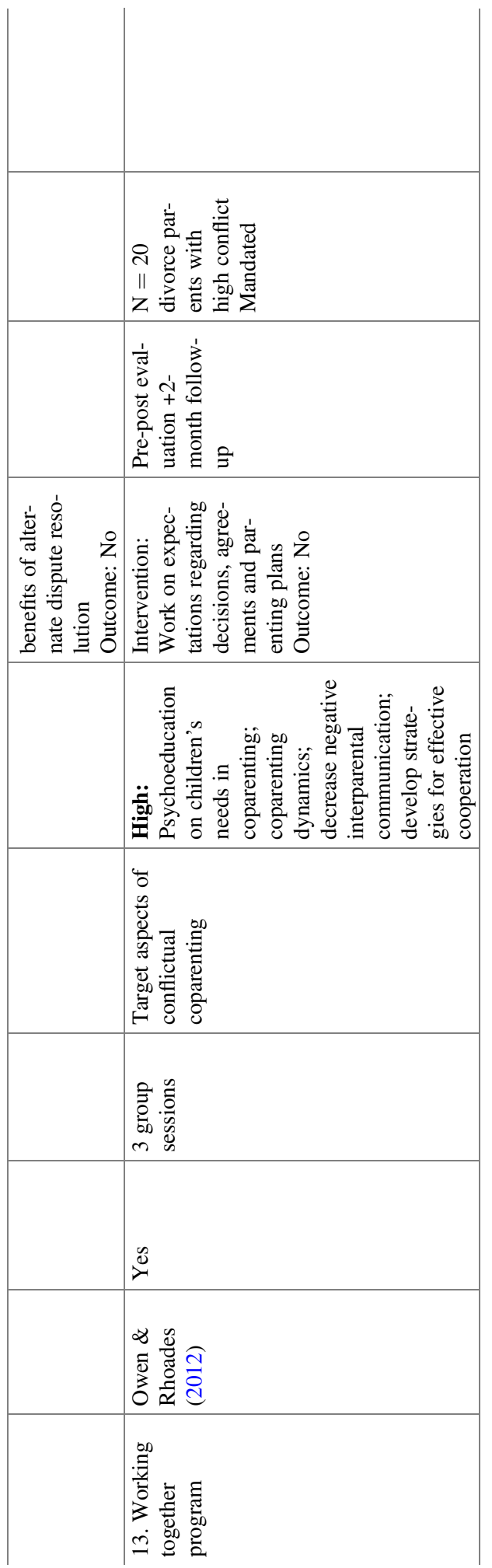




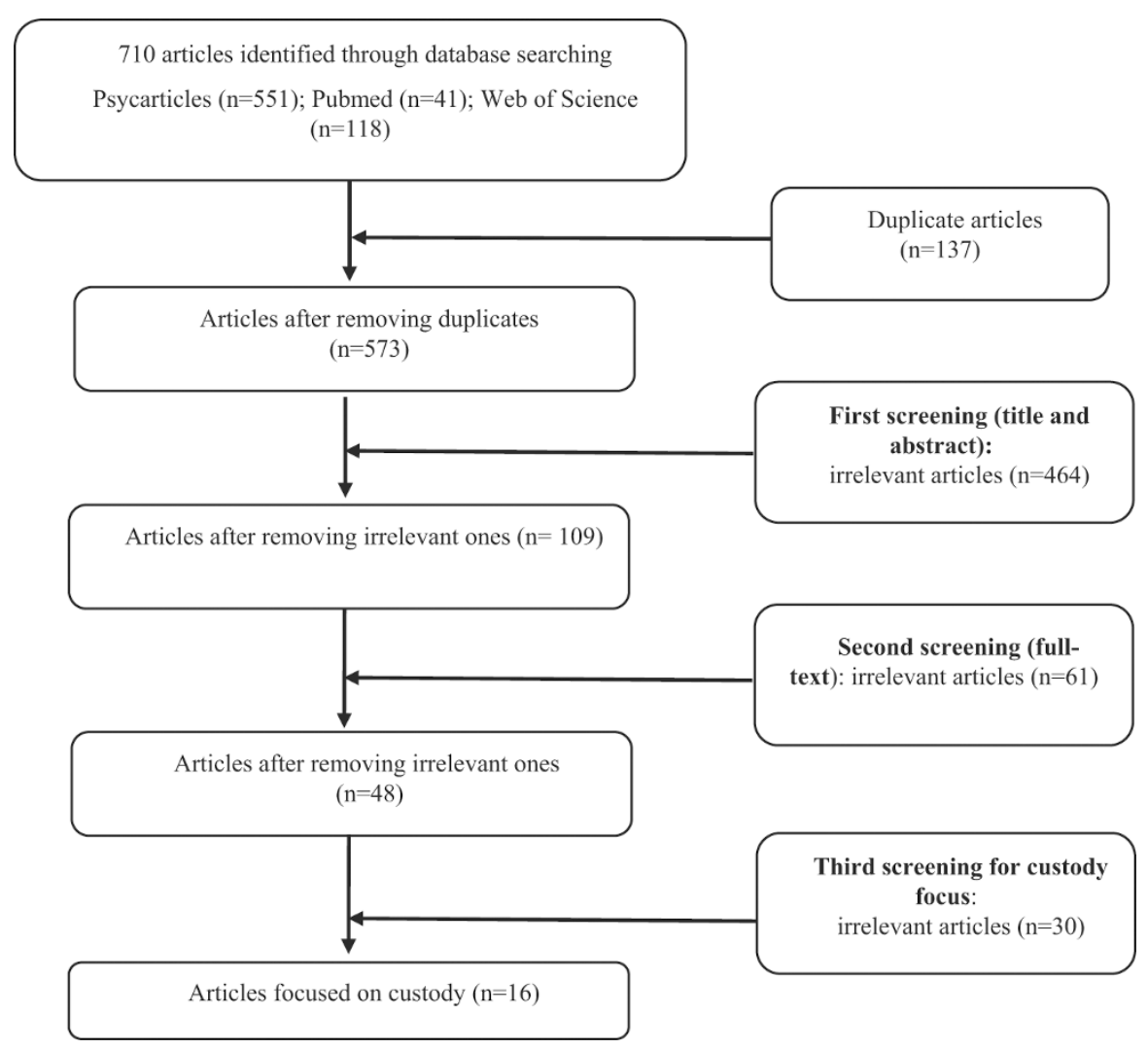

Fig. 12.1 Flow chart of the selection process

The main aims of these programs are presented by the authors as follows, with some programs having up to 4 different aims:

1. Work on the coparenting relationship, such as improving cooperation and managing of coparental conflict (Programs 2, 4, 5, 6, 9, 11, and 13);

2. Work on the implementation of, and compliance with, parenting plans or decisions related to custody, and empowering parents to make their own decisions about custody (Programs 3, 5, 6, 7, 8, 9, and 11);

3. Increase the awareness of the repercussions of divorce on children (Programs 1, 7, 8, 10, and 12);

4. Work on global communication skills and psychoeducation (Programs 5, 6, 9, and 10)

5. Work on communication skills to increase the child's well-being or adjustment (Programs 3, 4, 5, and 7); and

6. Enhance each parents' adjustment to the transition (Program 6).

As the programs were selected based on their coparenting and custody foci, these aims are naturally the most represented in the main goal of the programs. 
We also note that only one program (Pais por inteiro, Lamela et al. 2010) presented the parents' adjustment to the transition to divorce as a main goal. The 12 other programs' main goals rather concerned the children or the coparental coordination.

Work on the Coparenting Relationship The proportion of coparenting work differed according to the programs. We rated as high the programs that included clearly more than $50 \%$ of coparenting content in their intervention, medium those including about $50 \%$, and low those including clearly less than $50 \%$. The majority of programs were rated as high in coparenting focus $(\mathrm{N}=8)$, while a minority was rated as medium $(\mathrm{N}=3)$ or low $(\mathrm{N}=2)$. The main targeted coparenting aspects were the strengthening of skills to increase supportive coparenting and decrease conflictual coparenting, with some programs working more specifically to help keep the child out of conflict (Programs 2, 7, 9, 11, and 13) or including information about the importance of good coparenting for the child (Programs 1, 4, 5, 8, and 9).

Custody as a Target and/or as an Outcome For all the programs, work on the development, adjustment, and/or implementation of parenting plans was present. It is noteworthy that some of them also explicitly included more specific targets such as the discussion of legal issues (Programs 9, 10, and 12), the role of the residential and non-residential parent and the effects of father's absence on child outcome (Programs 10, 11, and 12), and strategies to ease the transitions between homes for children (Program 7).

A total of 5/13 programs also included the issue of custody as an outcome. These programs assessed their impact on reaching agreement (Programs 1, 3, and 11), satisfaction with or knowledge of the parenting plan (Programs 2, 3, and 10), improvement of the distribution of parenting time or provisions for coparental communication (Programs 1 and 3), and attitude towards the non-residential parent's role (Program 10). As the type of empirical validation was heterogeneous (RCT, pre-post measures, post-test measures only), as well as the sample sizes (less than 20 parents to about 2500 parents), the global picture of the outcomes obtained must be taken very cautiously.

Regarding the reaching of an agreement, the results were conflicted, with 2 programs having a positive impact (Programs 1 and 3 ) and one having a negative impact (Program 11) on reaching agreement. A total of 2 programs had a positive impact (Programs 2 and 3) and one had no impact (Program 10) on the satisfaction with the development of the parenting plan. Furthermore, a positive impact was observed in Programs 1 and 3 for the improvement of the distribution of parenting time or provisions for coparental communication, with some long-lasting effects 12 years after the intervention (Program 6); and no effect was observed for Program 10 regarding a change in attitude towards the non-residential parent role.

Conclusion This section allowed the identification of 13 post-divorce coparenting interventions that included the issue of SPC as a target of intervention and, for some of them, also as an outcome. These programs allow therapeutic work on the coparenting relationship with one of the aims being to facilitate the building of a parenting plan and/or to reduce the conflicts related to it. These programs are indeed offered to parents who are at different moments of the separation process, with some 
parents still in the process of discussing custody, and others more advanced in the process, e.g., parents who have already chosen a custody arrangement and are in court for payment issues.

However, how can we intervene on the coparenting relationship when the couple is still on the verge of separation? Will marital dissolution affect the coparenting dynamic or will the partners maintain a stable coparenting relationship despite separation? Will the issue of custody emerge at this stage, and how? In order to answer these questions, a case study is provided. It illustrates the trajectory of a distressed couple who entered couple therapy then decided to separate around the third therapy session. A clinical analysis of the case is provided and is combined with information gathered from independent assessment of the couple's progress, as they took part in a randomized controlled trial (RCT) in the context of their therapy. In the following section, we first describe the RCT and the methodology that was used to analyse the case (Pragmatic case study method; Fishman 2017), then present the results of the case analysis.

\subsection{Case Study: Coparenting While Separating}

\subsubsection{Method}

Through the case studies within RCT methodology (Fishman 2017), we may deepen our knowledge of how a treatment model is implemented, which contributes to our practical and theoretical knowledge of couple therapy with parents. The RCT in which Linda and Paul were involved aimed to assess the efficacy of a brief intervention for parents in intact families. In this trial, parents of a child (or stepchild) aged 16 years or younger and living in the same household participated in either a brief as-usual couple therapy or in an integrative brief systemic intervention (IBSI; Darwiche et al. 2017a, b) combining therapeutic work on romantic and coparenting relationships. Treatments were comparable in length and number of sessions. The brief as-usual couple therapy and the IBSI were both conducted by expert therapists trained in systemic psychotherapy. Couples were recruited from various therapy centres in the French-speaking part of Switzerland. The randomization allocated Linda and Paul to IBSI.

The aim of our case study analysis within this trial is not to assess the efficiency of IBSI but rather to illustrate the therapeutic process of a separating couple. The objective is to collect observations on a specific coparenting trajectory and on how custody-related issues were integrated within this trajectory.

The case study analysis was carried out using the pragmatic case study method (Fishman 2017), a small-scale research methodology that allows for the exploration of the processes and outcomes of an intervention. Following this method, the case of Linda and Paul was analysed with a detailed, session-by-session, qualitative approach based on the videotaped session material and on the therapist's feedback on the process. The clinical case analysis was then articulated by using the outcomes 
obtained through self-reported questionnaires and observational tasks. A synthesis of the pragmatic case study is proposed in this chapter.

Integrative Brief Systemic Intervention This manualised intervention is organized into six sessions spanning 6 months. In Session 1, the marital and/or coparenting difficulties are explored in order to get the partners involved as a marital dyad and as coparents. Sessions 2 to 5 represent the intervention phase during which work is conducted on the marital and coparenting vulnerabilities and on the resources that the partners can rely on. The therapist works on the spillover effects of one relationship on the other (e.g. negative emotions provoked by marital conflict transferring directly to coparenting interactions; Bonds and Gondoli 2007). With highly conflictual couples, a therapeutic lever is to raise the partners' awareness of the potentially harmful effects of their conflicts on their children. It is assumed to motivate the partners to work together for the sake of their children. Once more insightful of their children's needs, the parents may be better able to confront conflictual and deeply rooted couple problems (Oppenheim and Koren-Karie 2013). Session 6 is dedicated to reflecting on the intervention, its effects, and on possible follow-up sessions to the therapy. At each session, the clients' feedback is sought concerning their experience during the therapeutic process and the therapeutic relationship to maximize the mobilizing effect of the limited therapeutic timeframe.

IBSI was developed for couples in a romantic relationship; therefore, the manual does not directly include custody-related issues. However, as custody issues are directly linked to the role of coparent-a key target in IBSI-it is covered with couples such as Linda and Paul, who decide to separate during the intervention.

Therapist Linda and Paul's therapist is a psychologist who had completed a 5-year post-master's systemic psychotherapy program and who had 1 year of clinical experience with IBSI. She also attended supervision sessions throughout the study facilitated by the IBSI expert trainers.

Measures As research participants in the RCT, Linda and Paul completed several validated questionnaires and participated in videotaped discussions prior to the first and after the last IBSI session. The results of their three self-reported questionnaires measuring their individual symptomatology (Outcome Questionnaire 10; OQ ${ }^{\circledR} 10.2$; Lambert et al. 2005), coparenting alliance (Parenting Alliance Measure; PAM; Abidin and Konold 1999), and coparenting conflict and triangulation (2 subscales of the Coparenting Inventory for Parents and Adolescents; CI-PA; Teubert and Pinquart 2011) are presented below. The $O Q \circledR 10.2$ is a 10-item measure on a 5-point Likert scale (range 0-4) for a maximum score of 40, designed for the measurement of client functioning in relation to therapy. Higher scores indicate more distress, and a score of 17 is considered a conservative clinical cut-off (Rothballer Seelert et al. 2015). The PAM is a 20-item measure on a 5-point Likert scale (range 1-5) for a maximum score of 100, assessing the dimension of coparenting support; higher scores indicate more coparenting support. The $2 \mathrm{x}$ 8 -item subscales of the CI-PA assess the presence of coparenting conflict and 
triangulation of the child. Items are scored on a 5-point Likert scale (range 1-5) for an average score between 1 and 5. The mean of the two subscales is computed to indicate negative coparenting. A higher score indicates more negative coparenting.

During the videotaped discussions, Linda and Paul were invited to talk about topics they agreed and disagreed on regarding their coparenting relationship $(2 \times 5$ min discussions). Their interactions were assessed using a coding system (Darwiche et al. 2017a, b) assessing the following items: Shared emotion/enjoyment of child, Agreement or Accommodation, Competition, Endorsement, Triangulation, Mutual investment, Positive «we-ness » as parents, Problem solving, Defensiveness, and Pressure for change. Coding of the tasks was done by the 4 th author of this chapter, who is an expert trainer in the coding system.

This study received ethical approval from the Ethical Committee of the University of Lausanne in 2015. The personal data of Linda and Paul were anonymised.

\subsubsection{Results}

\section{Clinical Case Analysis}

Linda and Paul attended six IBSI therapy sessions with intervals of 3 weeks to 1 month between sessions. Both are in their forties and are employed in social work. They met at work 15 years ago and married 4 years later. They have two boys aged 10 and 8 and one 5-year-old daughter.

A Couple in High Marital and Coparenting Distress The first two sessions focused on each partner's personal background and on analysing each partner's request for couple therapy. The couple decided to enter psychotherapy after Paul cheated on Linda. Linda explains that there were several issues in the relationship and that she accepted her husband's habit of going out frequently. However, she feels that his unfaithfulness crossed a boundary. She is now expecting him to be more involved at home and with the children and to go out less often. She also threatens to leave him if he spends another night out. Paul feels that he has absolutely no space for decisionmaking at home and is dissatisfied with his wife's control over him.

The couple has been distressed for 5 years, since the birth of their last child. At the time, Paul was suffering from depression due to professional difficulties. Since then, Linda has taken it upon herself to help her husband overcome his depression. She considers that she has been taking care of everything related to the home and the children, leading her to feeling burned out. At this point of the session, Linda dominates the conversation, helping Paul finish his sentences, even though he speaks clearly. Linda seems to be the one in control, whereas Paul stays in the background.

Both describe important coparenting conflicts: Linda is unsatisfied with Paul's lack of involvement at home, and Paul feels similarly about Linda's lack of recognition of said involvement. The children are impacted by these difficulties, as they 
sometimes witness their parents' conflicts and express their fear of them disappearing, dying, or leaving them to be cared for by other people. Linda adds that they also worry about their father's health.

\section{Events that Led to the Separation Decision and Active Support from the Therapist}

to Protect the Children The third session is requested ahead of schedule after Linda's discovery of an expensive hotel bill. She is very upset and demands an explanation. Paul confesses to having been unfaithful again. Linda is clearly lost and rattled. Following this discovery, she is certain that she wants a separation and wants to immediately break the news to the children. Paul prefers to announce it after their family holiday. During this session, the therapist helps the couple determine an appropriate time and manner of explaining the decision to their children, and the parents agree that it will be shared after the holiday.

During this session, the atmosphere quickly becomes tense and reproaches are thrown left and right, in particular regarding the coparenting relationship: Linda does not trust in Paul's capacity to be alone with the children. Paul blames Linda for involving the kids in their conflicts and for pushing her fears on them. During this session, the therapist almost systematically interrupts Linda and Paul as soon as a marital dispute arises in the conversation to help them focus on the concrete ways in which they could protect their children from their personal issues. The therapist invites the parents to formally commit to avoid arguing in front of the children during the holiday. This step is not an easy one to take as they both have a lot of anger towards the other, as a parent and not only as a partner: Paul explains that his wife insinuates to the kids that he is a bad father; Linda angrily replies that the kids do not have a present father and that they can feel it. At that moment, the therapist tries to work towards better cooperative coparenting by underlining the risks of having children caught in the middle of a contentious separation. Furthermore, due to the risks of spillover from the marital conflict on the other family relationships, the therapist helps the parents remember the importance of the bond the other parent has with the children.

\section{Organization of the Separation and Custody-Related Questions: Strengthening} the Coparenting Relationship The fourth session focuses on the organizational aspects of the separation process. The parents were able to protect their children from their conflicts during the holiday and to discuss it calmly during the session. They succeeded in planning Paul's departure from the house and his future shared time with the kids, as well as the creation of separate bank accounts. The parents have decided to announce the separation to the kids the next day, and Paul asks the therapist for advice on how to share this decision with them. The idea of implementing SPC is also raised by Paul. Linda is preoccupied because of the psychological state of her husband, but both agree that this needs to be discussed again later, when the concrete changes linked to the separation will have been put in place (for example, Paul's new home). The therapist comments positively on the fact that the parents have been able to put things into perspective.

Linda and Paul realise that they are able to discuss the situation in a constructive way, even if tensions are still present. They hesitate between making the transition 
towards separation gradually (for example, by spending the weekends all together) and changing their habits more radically. In any case, they realise that taking the decision to separate has made them feel at peace. Paul hopes that they will still be bonded together: 'I would like the kids to feel that they have the love and attention of both their parents'. Both of them are willing to go on with therapy: 'It is now that we need your help, notably to discuss the custody issues'. For the first time since the beginning of the sessions, and now that the decision to separate is made, the therapist feels that they are able to set a clearer goal for the therapy: she suggests supporting Linda and Paul during the separation process, first as coparents, and later, as partners. That way they might be able to understand more deeply what happened in their romantic relationship and preserve the positive elements of their story.

Distress Due to the Ambiguity in Communication and Boundaries: Acknowledging the Marital Suffering, Supporting the Parenting and Coparenting Relationships By the fifth session, Paul has moved out and lives temporarily in a hotel. He prefers to wait and see how his health will evolve as well as his professional situation before moving into an apartment. He still comes often to the family home. This creates tensions regarding boundaries and personal space. The children reacted rather calmly to the separation, without expressing strong emotions, and were able to ask their parents many questions later.

Linda feels that she needs to look back to understand what happened to their romantic relationship. She blames Paul for not having been able to share his discontent towards her sooner. Paul believes that he tried but that she was not able to listen: during his first burnout for example, she refused to accept taking additional help with the kids and pressured Paul to help her instead. He feels that it is very difficult for him to forgive her for this episode. The therapist encourages them to give themselves time before revisiting these aspects of their relationship because their emotions are still too strong, and it is difficult for each of them to acknowledge the other's suffering. She also stresses that Linda and Paul were able to preserve the parent-child bond and that they even increased the trust they have for one another as parents.

\section{Moving Forward as Parents and Coparents, Despite Conflicts and Individual} Suffering The sixth session allows for further clarification of each parent's personal space. The geographical space is now better implemented. They report that they argued about one of their children in front of them, and that the children asked them to stop. However, they felt in this situation that they were more able to handle the conflicts in a cooperative way.

Paul is facing new professional difficulties, and he is feeling worse psychologically. However, this time, they have decided to get the help of an au pair. It seems that the separation has helped them in making these decisions, and this is a relief for both of them. Paul explains that it is worth learning how to better cooperate even though they were not able to do this during their marriage. Both want to go on with therapy after this last session. 


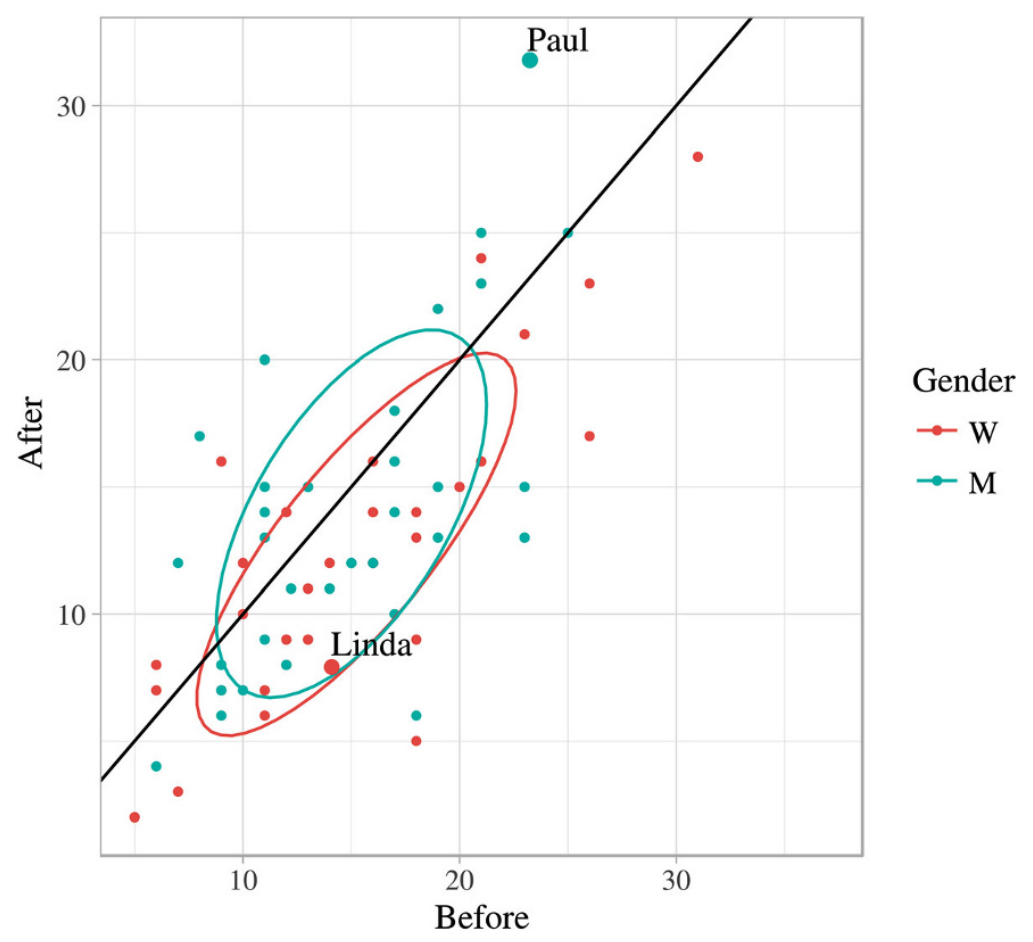

Fig. 12.2 Scores of Symptomatology (OQ). Note. Ranging from 0 to 40 . Clinical cut-off $=17$

\section{Pre-post Data for Questionnaires and Observational Tasks}

The pre-post therapeutic evolution for individual symptomatology, coparenting alliance, negative coparenting, as well as the quality of coparenting interactions is presented in graphs. Scatter plots were used to graphically illustrate the pre-post intervention scores of Linda and Paul, amongst the whole sample of the RCT ( $\mathrm{N}=35$ couples having completed an IBSI). The results are illustrated for individual symptomatology (Fig. 12.2), coparenting alliance (Fig. 12.3), and negative coparenting (Fig. 12.4). The trend line represents the absence of change; scores indicating progress in coparenting alliance are located above this line, and scores indicating a decrease in individual symptomatology and in negative coparenting are located below this line. The confidence ellipses visually show the area that contains $50 \%$ of the individuals.

Individual Symptomatology Paul scored above the clinical cut-off of 17 (Rothballer Seelert et al. 2015) before therapy, and his individual level of distress then increased from before to after the sixth session (23 to 32). Paul's scores were exceptionally high compared to $50 \%$ of the group (Cf. Figure 12.2). Linda, on the other hand, scored below the clinical cut-off before therapy, and her level of symptomatology decreased during the course of therapy (14 to 8); her scores were similar to 50\% of 


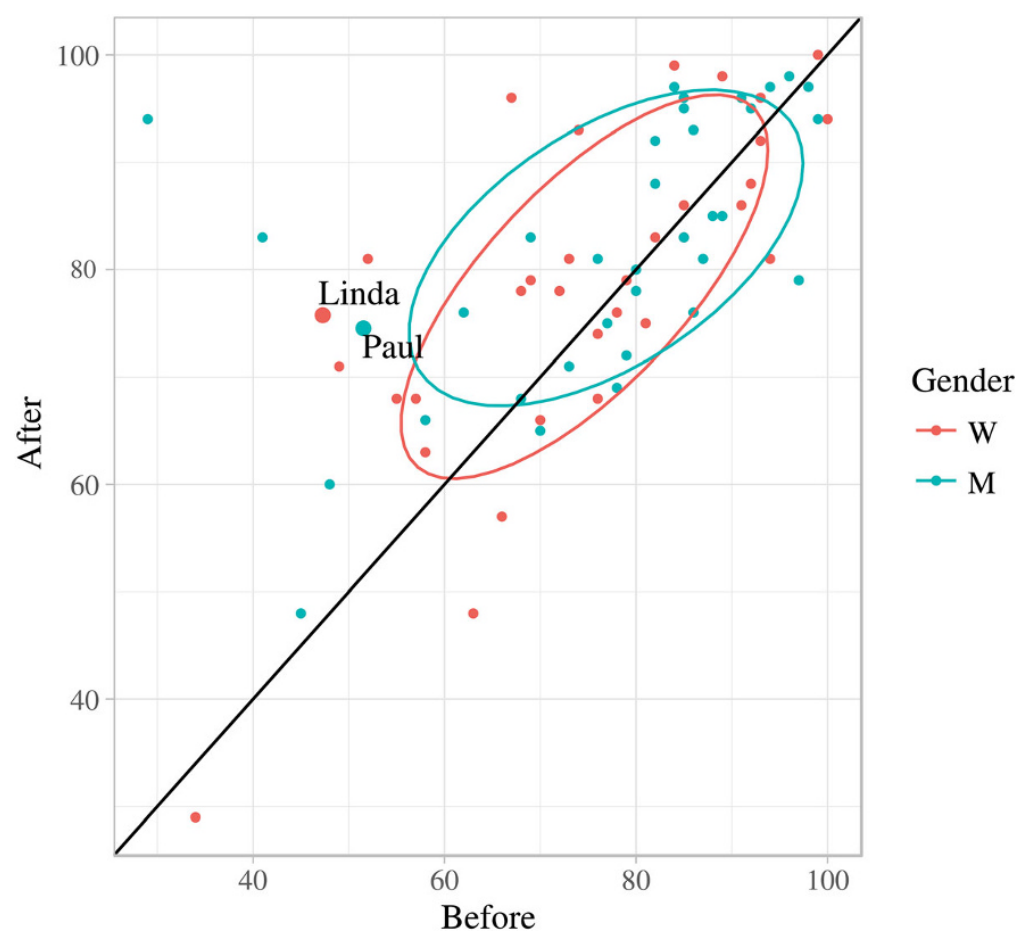

Fig. 12.3 Scores of Coparenting Alliance (PAM). Note. Ranging from 20 to 100

the group (Cf. Figure 12.2). These results are in line with what Paul expressed during therapy: he felt severe personal distress, particularly towards the end of therapy as he was facing professional difficulties and may have been suffering also from having left the family home. Linda's low level of symptomatology before therapy may be related to the fact that she was trying to manage the whole family and had to rely on all her personal energy: 'I cannot allow myself to be overloaded while my husband is in distress'.

Coparenting Alliance Both parents' perception of their coparenting alliance significantly improved during the course of therapy in spite of the separation (51 to 75 for Paul, and 47 to 76 for Linda). In comparison with $50 \%$ of the participants (Cf. Fig. 12.3), their scores were lower before therapy but improved remarkably (e.g. for items such as 'I believe the other parent is a good parent' or 'I feel good about my child's other parent's judgment about what is right for our child'). Paul and Linda's evaluation, therefore, confirmed the clinical analysis that showed strengthened cooperative coparenting at the end of the six sessions: Paul got more involved with the kids, and Linda recognised his efforts.

Negative Coparenting The data show a slight increase in negative coparenting for Linda $(0.4$ to 0.9$)$; her scores however remain close to $50 \%$ of the participants 


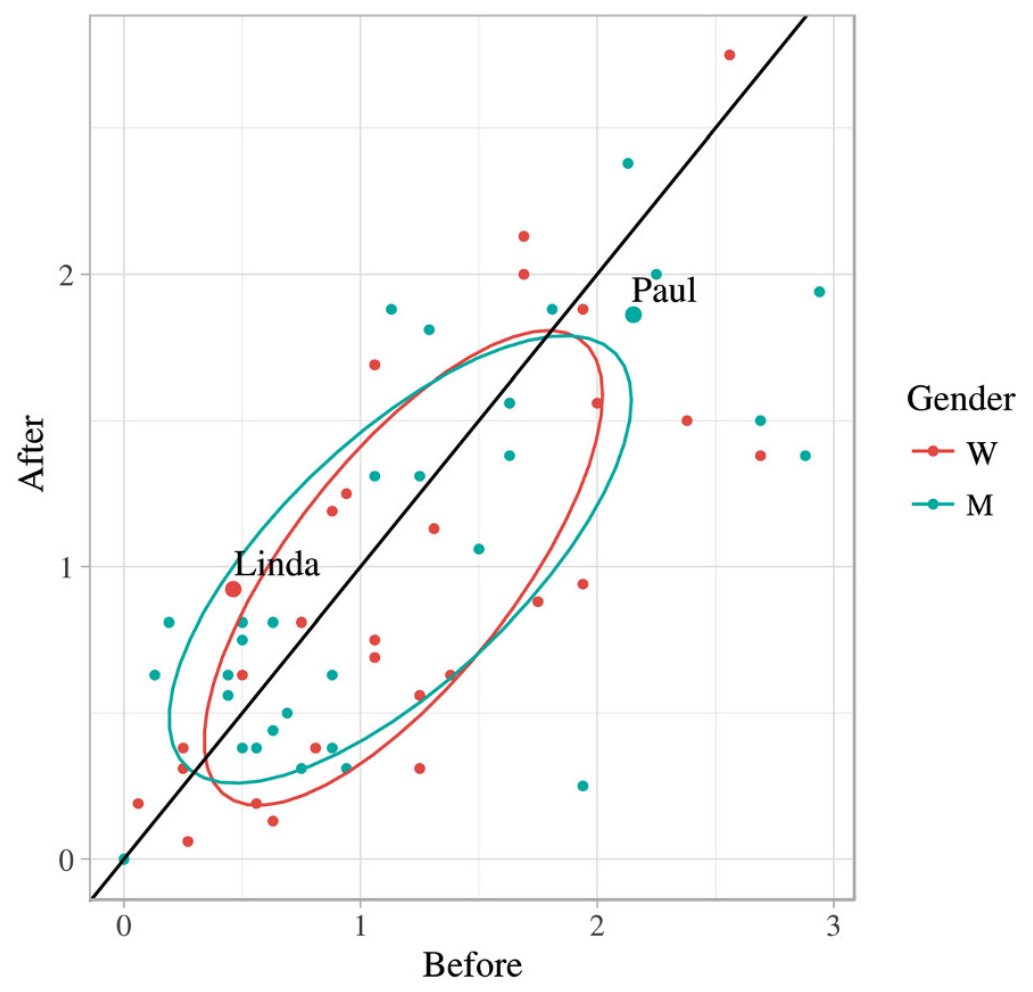

Fig. 12.4 Scores of Negative Coparenting (CIPA). Note. Ranging from 0 to 5

(Cf. Figure 12.4). Paul's scores were higher than $50 \%$ of the group but a slight decrease in his perception of negative coparenting was observed (2.1 to 1.9). This result may be related to the higher level of conflict and risk of triangulation of the child that Linda and Paul experience due to the separation process, but which does not prevent them from coparenting improvement (increase of coparenting alliance and, for Paul, decrease of negative coparenting).

Quality of Coparenting Interactions Coding from the observational tasks showed a higher rate of shared emotion, validation, and involvement (agreement task); and a higher rate of agreement, validation, and problem resolution as well as a decrease in defensiveness (disagreement task), when comparing pre-and post-results. The other items remained stable, and a decrease of shared emotion was observed during the disagreement task. These results are in line with the clinical analysis: despite the high number of difficulties, Linda and Paul's coparenting interactions improved during the course of therapy. 


\section{Discussion}

During this couple therapy, the therapist appeared to support the parents, allowing Paul - who was in personal distress - to maintain and even increase his involvement as a father and a coparent (Kamp Dush et al. 2011). This can be considered to be a positive evolution for these parents, as they functioned in a significantly imbalanced way during their marriage; Linda was the family manager, while Paul remained in the background. In this case study, the decision to separate helped Paul to be more involved and Linda to step back from the risk of being a gatekeeping mother (Pruett et al. 2007). The case analysis showed that the discontinuity hypothesis (when the coparenting dynamic is modified by the separation) may be the conclusive one: the decision to separate has influenced the coparenting dynamic in a positive way and in turn, the more functional coparenting dynamic seems to foreshadow a positive outcome for SPC. Although it may be hard to prove, it is likely that couple therapy facilitated this improvement, all the more because both parents were fully engaged in the therapeutic process.

Regarding spillover effects, the analysis of the therapeutic process shows that the therapist had to actively step in to limit the impact of marital issues on the coparenting relationship and therefore on the children (Teubert and Pinquart 2010). Little by little, Linda and Paul were able to learn to make this a priority. The therapist worked on enhancing this ability by constantly acknowledging their respective suffering while also placing it into perspective (Lebow 2008). The data gathered from the therapist after the sixth session indicates that the divorce process and the SPC are running their course. Changes were also observed in the children, as reported by the parents (Amato and Afifi 2006). The youngest child-who was very agitated before the separation - is now calmer, whereas the oldest child-who was taking on too many adult responsibilities - is now more able to disclose his emotions and the difficulties he is facing. The therapist also pointed out that the parents became more aware of their children's behaviors; for example, Linda realized after the sixth session that before this stage, she did not notice how worried the children were for their parents because she was too wrapped up in her marital distress. This observation clearly illustrates the presence of spillover effects and highlights the importance of untangling these effects during therapy to minimize the negative fallouts of marital distress, both before and after separation.

To conclude, this couple therapy case study illustrates the high risks of spillover from feelings of anger, resentment, and humiliation experienced in the marital relationship for the other family relationships. However, Linda and Paul had the necessary resources to keep their children's well-being at the center of their concern, even with the additional weight of the father's depression. It can be expected that the discussions regarding SPC will benefit from this more positive atmosphere between them and that the goal of SPC will contribute to reinforcing this new dynamic, within the secure context of therapy. 


\subsection{Discussion and Conclusion}

This chapter aimed to address the question of SPC from the perspective of coparenting and, more specifically, from the prism of coparenting-based interventions, as coparenting is considered a central factor of family dynamics, before and after separation or divorce (Pruett and Donsky 2011; McHale and Irace 2011).

The literature review of existing coparenting-based programs targeting custodyrelated issues showed that parents have a choice of several types of help, from a selfstudy handbook to more intensive parent groups sessions, or a mix of individual, joint, and child-inclusive sessions. These interventions may assist them in strengthening their coparenting relationship, better managing their interparental conflicts, and being more aware of the risks of their children being caught in the middle of their conflicts. The help sessions may also help parents to develop a parenting plan, adjust it to their children's developmental needs, and discuss legal issues or work toward an agreement in the case of custody disputes. However, research on the impact of these programs on custody-related aspects is scarce and the results vary. More studies are needed to assess these programs using rigorous methods-such as randomized control trials - to confirm findings. An effort should also be made to consistently include custody-related aspects in the curriculum of these programs and in the outcomes, which would contribute toward increasing our knowledge of the impact of the programs on these specific aspects. More research is also needed to identify specific therapeutic strategies and skills required to help distressed couples work together toward reaching a custody agreement.

The case study allowed us to explore more thoroughly the therapeutic process of a separating couple, to gain insight into how a cooperative coparenting relationship can develop, and how custody-related issues may be discussed, despite the difficulties associated with separation. The clinical case analysis, as well as the results obtained regarding the parents' individual symptomatology, coparenting alliance, and negative coparenting, highlighted the fact that it is possible for severe personal distress and acute suffering within the marital relationship to coexist with the development of effective coparenting. However, the case analysis also showed that there is a fine line between succeeding and failing, as a cooperative coparenting team could be overwhelmed by feelings of sadness and hostility due to the dissolution of their marriage. In this situation, Paul and Linda certainly benefited from being in couple therapy; they wanted to continue to engage in such therapy to help them face the many changes they needed to adapt to and to be able to discuss the opportunities offered by SPC in a trusting environment. In Linda and Paul's situation, some discontinuity was observed in the experience of being a coparenting team. The decision to separate appears to have positively impacted their coparenting relationship, rebalancing Linda and Paul's roles as parents and coparents and clarifying their personal space. This supports the discontinuity hypothesis.

We can assume that the positive evolution of Linda and Paul's coparenting relationship may be an asset for implementing SPC; in turn, the opportunity of a SPC scenario may be a powerful way of giving both parents the opportunity to be involved with their children and to cooperate with one another. The SPC scenario 
may also reinforce parents' commitment to work as a coparenting team, thereby providing a protective factor from the distancing and disengagement of vulnerable parents (those in similar situations to Paul in the case study).

Limitations This work has the following limitations. The first limitation is that only published and available information was retrieved for our review. The authors of the reviewed material were not contacted for further information, which may have been relevant regarding incomplete information (e.g. manual). The next limitation involves generalizing from a case study. This could be a sensitive process, as Linda and Paul's experience of the transition from marriage to separation and divorce was obviously unique. One cannot completely exclude the possibility that the observed changes in Linda and Paul may be due to other processes, rather than the intervention itself. Nevertheless, as mentioned in the method section, pragmatic case studies are increasingly recognized as contributing to the building of evidence for intervention practice and theory (McLeod and Elliott 2011). Case studies provide research that is practitioner-friendly by showing how an intervention applies to a specific case (Fishman 2017). However, a future step should be to accumulate more cases such as that of Linda and Paul, followed within different types of interventions, to increase the generalizability of our observations. These observations also need to be combined with the quantitative data from RCTs to increase our understanding of the creation of a SPC scenario during the transition from marriage to divorce.

Conclusion Any effort to ease the transition of care between mental health professionals who specialize in therapy for married couples and those who specialize in post-divorce mediation could certainly be beneficial for the couples and shape their emotional experience of coparenting during marriage, the separation process, and after a divorce. This could be achieved through more suitable training of couples and family therapists regarding the specific information and/or required skills to address legal decisions and child-custody arrangements. These benefits may also be achieved by improved coordination between therapists of divorced couples and therapists of married couples. This is of great importance as custody challenges, including SPC, are inextricably linked to how parents raise their children.

Acknowledgements This chapter also benefited from the support of the Centre for Population, Family and Health (CPFH) at the University of Antwerp which enabled Open Access.

Funding This work was supported by the Swiss National Science Foundation (Grant $N^{\circ} 100019$ 159437).

\section{References}

Abidin, R. R., \& Konold, T. R. (1999). Parenting alliance measure professional manual. Odessa: Psychological Assessment Resources. 
Adamsons, K., \& Pasley, K. (2006). Coparenting following divorce and relationship dissolution. In M. A. Fine \& J. H. Harvey (Eds.), Handbook of divorce and relationship dissolution (pp. 241-261). Mahwah: Lawrence Erlbaum Associates Publishers.

Ahrons, C. R. (2007). Family ties after divorce: Long-term implications for children. Family Process, 46(1), 53-65.

Amato, P. R., \& Afifi, T. D. (2006). Feeling caught between parents: Adult children's relations with parents and subjective well-being. Journal of Marriage and Family, 68, 222-235. https://doi. org/10.1111/j.1741-3737.2006.00243.x.

Arbuthnot, J., Poole, C. J., \& Gordon, D. A. (1996). Use of educational materials to modify stressful behaviors in post-divorce parenting. Journal of Divorce \& Remarriage, 25(1-2), 117-137. https://doi.org/10.1300/J087v25n01_08.

Ballard, R. H., Holtzworth-Munroe, A., Applegate, A. G., D’Onofrio, B. M., \& Bates, J. E. (2013). A randomized controlled trial of child-informed mediation. Psychology, Public Policy, and Law, 19(3), 271-281. https://doi.org/10.1037/a0033274.

Bonds, D. D., \& Gondoli, D. M. (2007). Examining the process by which marital adjustment affects maternal warmth: The role of coparenting support as a mediator. Journal of Family Psychology, 21(2), 288-296. https://doi.org/10.1037/0893-3200.21.2.288.

Booth, A., \& Amato, P. R. (2001). Parental predivorce relations and offspring postdivorce wellbeing. Journal of Marriage and the Family, 63, 197-212.

Bowers, J. R., Ogolsky, B. G., Hughes, R., Jr., \& Kanter, J. B. (2014). Coparenting through divorce or separation: A review of an online program. Journal of Divorce \& Remarriage, 55(6), 464-484. https://doi.org/10.1080/10502556.2014.931760.

Braver, S. (2014). The costs and pitfalls of individualizing decisions and incentivizing conflict: A comment on Afcc's think tank report on shared parenting. Family Court Review, 52(2), $175-180$.

Brown, J. H., Bledsoe, L., Yankeelov, P., Christensen, D., Rowan, N. L., \& Cambron, M. L. (2009). PACT: A collaborative team model for treating high conflict families in family court. Juvenile and Family Court Journal, 60(2), 49-67. https://doi.org/10.1111/j.1755-6988.2009.01026.x.

Choi, J.-K., Hatton-Bowers, H., Brand, G., Poppe, L. M., \& Foged, J. (2017). Co-parenting for successful kids: Impacts and implications. Journal of Extension, 55(6), UNSP 6RIB1.

Choi, J.-K., Parra, G., \& Jiang, Q. (2019). The longitudinal and bidirectional relationships between cooperative coparenting and child behavioral problems in low-income, unmarried families. Journal of Family Psychology, 33, 203-214. https://doi.org/10.1037/fam0000498.

Christopher, C., Umemura, T., Mann, T., Jacobvitz, D., \& Hazen, N. (2015). Marital quality over the transition to parenthood as a predictor of coparenting. Journal of Child and Family Studies, 24, 3636-3651. https://doi.org/10.1007/s10826-015-0172-0.

Cox, M. J., \& Paley, B. (1997). Families as systems. Annual Review of Psychology, 48, 243-267. https://doi.org/10.1146/annurev.psych.48.1.243.

Darwiche, J., Imesch, C., \& Eira Nunes, C. (2017a). Système de codage des interactions conjugales et coparentales. Manuscrit inédit, Institut de psychologie. Lausanne: Université de Lausanne.

Darwiche, J., Carneiro, C., Vaudan, C., Imesch, C., Eira Nunes, C., Favez, N., \& de Roten, Y. (2017b). Parents in couple therapy: An intervention targeting the romantic and the coparental relationships. Manuscrit in revision.

Emery, R. E. (2012). Renegociating family relationships. New York/London: The Guildford Press.

Emery, R. E., Matthews, S. G., \& Wyer, M. M. (1991). Child custody mediation and litigation: Further evidence on the differing views of mothers and fathers. Journal of Consulting, 59(3), 410-418. https://doi.org/10.1037/0022-006X.59.3.410.

Emery, R. E., Matthews, S. G., \& Kitzmann, K. M. (1994). Child custody mediation and litigation: Parents' satisfaction and functioning one year after settlement. Journal of Consulting, 62(1), 124-129.

Emery, R. E., Laumann-Billings, L., Waldron, M. C., Sbarra, D. A., \& Dillon, P. (2001). Child custody mediation and litigation: Custody, contact, and coparenting 12 years after initial dispute resolution. Journal of Consulting, 69(2), 323-332.

Favez, N. (2017). Psychologie de la coparentalité. Paris: Dunod. 
Fishman, D. B. (2017). The pragmatic case study in psychotherapy: A mixed methods approach informed by psychology's striving for methodological quality. Clinical Social Work Journal, 45 (3), 238-252.

Higgins, J. P. T., \& Green, S. (2008). Cochrane handbook for systematic reviews of interventions. Chichester: Wiley.

Kamp Dush, C. M., Kotila, L. E., \& Schoppe-Sullivan, S. J. (2011). Predictors of supportive coparenting after relationship dissolution among at-risk parents. Journal of Family Psychology, 25(3), 356-365.

Kitzmann, K. M. (2000). Effects of marital conflict on subsequent triadic family interactions and parenting. Developmental Psychology, 36, 3-13. https://doi.org/10.1037//0012-1649.36.1.3.

LaGraff, M. R., Stolz, H. E., \& Brandon, D. J. (2015). Longitudinal program evaluation of « Parenting Apart: Effective Co-Parenting. ». Journal of Divorce \& Remarriage, 56(2), 117-136. https://doi.org/10.1080/10502556.2014.996044.

Lambert, M. J., Finch, A. M., Okiishi, J., \& Burlingame, G. (2005). Administration and scoring manual for the OQ10.2. Salt Lake City: OQ Measures LLC.

Lamela, D., \& Figueiredo, B. (2016). Coparenting after marital dissolution and children's mental health: A systematic review. Jornal de Pediatria, 92(4), 331-342.

Lamela, D., Castro, M., \& Figueiredo, B. (2010). Pais por inteiro: Avaliação preliminar da eficácia de uma intervenção em grupo para pais divorciados. [Preliminary efficacy evaluation of a group intervention program for divorced parents.]. Psicologia: Reflexão e Crítica, 23(2), 334-344. https://doi.org/10.1590/S0102-79722010000200016.

Le, Y., McDaniel, B. T., Leavitt, C. E., \& Feinberg, M. E. (2016). Longitudinal associations between relationship quality and coparenting across the transition to parenthood: A dyadic perspective. Journal of Family Psychology, 30, 918-926. https://doi.org/10.1037/fam0000217.

Lebow, J. (2008). Separation and divorce issues in couple therapy. In A. Gurman (Ed.), Clinical handbook of couple therapy (pp. 459-477). New York: Guilford.

Leclair, V., St-Amand, A., \& Bussières, E.-L. (2018). Association between child custody and postseparation coparenting: A meta-analysis. Canadian Psychology/Psychologie Canadienne, 60(2), 90-101. https://doi.org/10.1037/cap0000140.

Lee, C. M., Picard, M., \& Blain, M. D. (1994). A methodological and substantive review of intervention outcome studies for families undergoing divorce. Journal of Family Psychology, $8(1), 3$.

Mangelsdorf, S. C., Laxman, D. J., \& Jessee, A. (2011). Coparenting in two-parent nuclear families. In J. P. McHale (Ed.), Coparenting: A conceptual and clinical examination of family systems (pp. 39-59). Washington, DC: American Psychological Association.

Martin, M. J., Sturge-Apple, M. L., Davies, P. T., Romero, C. V., \& Buckholz, A. (2017). A process model of the implications of spillover from coparenting conflicts into the parent-child attachment relationship in adolescence. Development and Psychopathology, 29, 417-431. https://doi. org/10.1017/S0954579417000086.

McHale, J. P., \& Irace, K. (2011). Coparenting in diverse family systems. In J. P. McHale \& K. M. Lindahl (Eds.), Coparenting: A conceptual and clinical examination of family systems (pp. 15-37). Washington, DC: American Psychological Association.

McHale, J. P., \& Lindahl, K. M. (2011). Coparenting: A conceptual and clinical examination of family systems. Washington, DC: American Psychological Association.

McKenry, P. C., Clark, K. A., \& Stone, G. (1999). Evaluation of a parent education program for divorcing parents. Family Relations: An Interdisciplinary Journal of Applied Family Studies, 48, 129-137. https://doi.org/10.2307/585076.

McLeod, J., \& Elliott, R. (2011). Systematic case study research: A practice-oriented introduction to building an evidence base for counselling and psychotherapy. Counselling and Psychotherapy Research, 11(1), 1-10.

Morril, M., Hines, D. A., Mahmood, S., \& Cordova, J. V. (2010). Pathways between marriage and parenting for wives and husbands: The role of coparenting. Family Process, 49, 59-73. https:// doi.org/10.1111/j.1545-5300.2010.01308.x. 
Murphy, S. E., Jacobvitz, D. B., \& Hazen, N. L. (2016). What's so bad about competitive coparenting? Family-level predictors of children's externalizing symptoms. Journal of Child and Family Studies, 25(5), 1684-1690. https://doi.org/10.1007/s10826-015-0321-5.

Nielsen, L. (2017). Re-examining the research on parental conflict, coparenting, and custody arrangements. Psychology, Public Policy, and Law, 23(2), 211.

Oppenheim, D., \& Koren-Karie, N. (2013). The insightfulness assessment: Measuring the internal processes underlying maternal sensitivity. Attachment and Human Development, 15(5-6), 545-561. https://doi.org/10.1080/14616734.2013.820901.

Owen, J., \& Rhoades, G. K. (2012). Reducing interparental conflict among parents in contentious child custody disputes: An initial investigation of the working together program. Journal of Marital and Family Therapy, 38(3), 542-555. https://doi.org/10.1111/j.1752-0606.2010. 00215.x.

Pruett, M. K., \& Donsky, T. (2011). Coparenting after divorce: Paving pathways for parental cooperation, conflict resolution, and redefined family roles. In J. P. McHale \& K. M. Lindahl (Eds.), Coparenting: Theory, research, and clinical applications (pp. 231-250). Washington, DC: American Psychological Association.

Pruett, M. K., Arthur, L. A., \& Ebling, R. (2007). The hand that rocks the cradle: Maternal gatekeeping after divorce. Pace Law Review, 27(4), 709-739.

Pruett, M. K., Ebling, R., \& Cowan, P. A. (2011). Pathways from a US co-parenting intervention to legal outcomes. International Journal of Law, Policy and the Family, 25(1), $24-45$.

Quigley, C., \& Cyr, F. (2017). Children's perspectives on parenting coordination: Insights from the Montreal parenting coordination pilot project. Journal of Child Custody: Research, Issues, and Practices, 14(2-3), 151-174. https://doi.org/10.1080/15379418.2017.1371093.

Rothballer Seelert, K., Hill, R. D., Rigdon, M. A., \& Schwenzfeier, E. (2015). Measuring patient distress in primary care. Clinical Research and Methods, 31(7), 483-487.

Rudd, B. N., Ogle, R. K., Holtzworth-Munroe, A., Applegate, A. G., \& D’Onofrio, B. M. (2015). Child-informed mediation study follow-up: comparing the frequency of relitigation following different types of family mediation. Psychology Public Policy and Law, 21, 452-457. https:// doi.org/10.1037/law0000046.

Rudd, B. N., Poladian, A. R., Holtzworth-Munroe, A., Applegate, A. G., \& D’Onofrio, B. M. (2017). Randomized control trial follow-up: Online program and waiting period for unmarried parents in title IV-D court. Journal of Family Psychology, 31, 381-386. https://doi.org/10.1037/ fam0000255.

Schoppe-Sullivan, S. J., Mangelsdorf, S. C., Frosch, C. A., \& McHale, J. L. (2004). Associations between coparenting and marital behavior from infancy to the preschool years. Journal of Family Psychology, 18, 194-207. https://doi.org/10.1037/0893-3200.18.1.194.

Steinbach, A. (2018). Children's and parents' well-being in joint physical custody: A literature review. Family Process, 58(2), 353-369. https://doi.org/10.1111/famp.12372.

Stolz, H. E., Sizemore, K. M., Shideler, M. J., LaGraff, M. R., \& Moran, H. B. (2017). Parenting together: Evaluation of a parenting program for never-married parents. Journal of Divorce \& Remarriage, 58, 358-370. https://doi.org/10.1080/10502556.2017.1322855.

Stroud, C. B., Meyers, K. M., Wilson, S., \& Durbin, C. E. (2015). Marital quality spillover and young children's adjustment: Evidence for dyadic and triadic parenting as mechanisms. Journal of Clinical Child \& Adolescent Psychology, 44, 800-813. https://doi.org/10.1080/15374416. 2014.900720.

Sullivan, M. J. (2008). Coparenting and the parenting coordination process. Journal of Child Custody, 5. https://doi.org/10.1080/15379410802070351.

Teubert, D., \& Pinquart, M. (2010). The association between coparenting and child adjustment: A meta-analysis. Parenting: Science and Practice, 10(4), 286-307.

Teubert, D., \& Pinquart, M. (2011). The Coparenting Inventory for Parents and Adolescents (CI-PA): Reliability and validity. European Journal of Psychological Assessment, 27(3), 206-215. 
Wallerstein, J. S., Lewis, J., Blakeslee, S., \& McIntire, K. (2000). The unexpected legacy of divorce: A 25 year landmark study (Vol. 77). New York: Hyperion.

Joëlle Darwiche is an associate professor of couple and family psychology at the Institute of Psychology of the University of Lausanne. She is the director of the Family and Development research center (FADO) of the University of Lausanne, a research lab that promote research in family and developmental psychology and encourage dialogue between researchers and practitioners. She is also a certified couple and family psychotherapist and director of the Master of Advanced Studies in systemic psychotherapy at the University of Lausanne. Her research mainly focuses on couple and family dynamics and on the evaluation of clinical interventions. She has published on transition to parenthood, couple therapy, and family interactions, assessed in various types of families and at different stages of life.

Cindy Eira Nunes is a SNSF (Swiss National Science Foundation) doctoral student at the Institute of Psychology and a member of the FAmily and DevelOpment research center (FADO) at the University of Lausanne, Switzerland. Her research focuses on couple psychotherapy and, more specifically, on the analysis of coparenting improvement during couple therapy for parents. She has published a meta-analysis and systematic review on the efficacy of programs integrating coparenting work for couples and families.

Nahema El Ghaziri is a research fellow at the migrant care unit of the University Center for Primary Care and Public Health of Lausanne, Switzerland. Her research interests are in the field of family dynamics. Her PhD focused on self-esteem and the quality of the parental couple relationships. She currently works on understanding the effects of forced migration on the family unit.

Camille Imesch M.Sc., is an SNSF (Swiss National Science Foundation) junior researcher at the Institute of Psychology and a member of the Family and Development Research Center (FADO) at the University of Lausanne, Switzerland. She also has a Master of Advances Studies in systemic psychotherapy and works in private practice as couple and family therapist.

Séverine Bessero M.Sc., has a Master of Advances Studies in systemic psychotherapy. She practices as a clinical psychologist and psychotherapist with fifteen years' therapeutic experience with couples and families. She is currently working in the Specialized Programme for Family and Couple Therapy of the Geneva University Hospitals, Geneva, Switzerland.

Open Access This chapter is licensed under the terms of the Creative Commons Attribution 4.0 International License (http://creativecommons.org/licenses/by/4.0/), which permits use, sharing, adaptation, distribution and reproduction in any medium or format, as long as you give appropriate credit to the original author(s) and the source, provide a link to the Creative Commons license and indicate if changes were made.

The images or other third party material in this chapter are included in the chapter's Creative Commons license, unless indicated otherwise in a credit line to the material. If material is not included in the chapter's Creative Commons license and your intended use is not permitted by statutory regulation or exceeds the permitted use, you will need to obtain permission directly from the copyright holder.

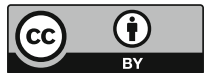

